\title{
Impact of compliance on quit rates in a smoking cessation intervention: population study in Denmark
}

\author{
Nermin Ghith ${ }^{1}$, Anne Birgitte Ammari ${ }^{2}$, Mette Rasmussen ${ }^{1}$, Anne Frølich ${ }^{3}$, Katy Cooper ${ }^{4}$, \\ Hanne Tønnesen ${ }^{1}$
}

\begin{abstract}
Objectives Primary objective was to evaluate whether patients completing at least $75 \%$ of the smoking cessation program had a higher quit rate after 6 months than patients participating in less than $75 \%$ of the program. Secondary objective was to evaluate whether there might be a more appropriate compliance level than $75 \%$.

Methods The study included all patients $(17,439)$ who participated in the National Gold Standard Smoking Cessation Program in Denmark (GSP) with planned follow-up for smoking cessation at 6 months. Patients were randomly divided into two groups (datasets) in order to investigate and re-validate the objectives on two separated groups of smokers. Sensitivity analyses were undertaken for non-responders.

Results Patients who completed at least $75 \%$ of the program sessions had higher quit rates in comparison to patients who completed less than $75 \%$ of the program $(\mathrm{OR}=0.27 ; 95 \% \mathrm{Cl} 0.24-0.31$ and $0.31 ; 0.27-0.35)$ for the first and second dataset, respectively. However patients who completed the whole program had higher quit rates compared to patients completing only $75 \%(0.49 ; 0.43-0.56$, and $0.54 ; 0.47-0.62$, respectively). The sensitivity analysis showed that baseline characteristics were similar between patients with missing and available follow-up data.

Conclusion Compliance to $75 \%$ of the national smoking cessation program (GSP) is shown to be effective; however, $100 \%$ compliance leads to even higher quit rates.
\end{abstract}

\section{About the AUTHORS}

1 WHO-CC, Clinical Health Promotion Centre, Bispebjerg University Hospital, Denmark

2 Palliative Medical Dept., Bispebjerg University Hospital, Denmark 3 Department of Integrated Health Care, Bispebjerg University Hospital, Denmark

4 School of Health and Related Research (ScHARR), University of Sheffield, England.

Contact: Nermin Ghith nermin_ghith@hotmail.com

\section{Introduction}

According to the Danish Cancer Society, around $20 \%$ of Danes aged 15 years and older were daily smokers in 2010 (1). Moreover, it is estimated that over 800,00o Danes are daily smokers, and around 14,00o Danes die annually due to smoking, while 4,500 die of cancer, where smoking is one of the main contributing risk factors. Consequently, Danish public health and tobacco control strategies include nationwide smoking cessation interventions. A national smoking cessation database (SCDB) was established to monitor and improve the clinical quality of smoking cessation programs (2). The leading and dominant intervention on smoking cessation in Denmark is a comprehensive evidence based intervention called the Gold Standard Program (GSP) (3). This program combines pharmacotherapy and psychological interventions in an intensive 6 week manual-based program; such an approach has been shown to be more effective than less intense interventions $(4 ; 5)$. For instance, such in- tensive programs on smoking cessation are the ones considered most relevant for hospitalised patients (6).

The program is delivered as a group or individual intervention by trained counsellors to patients who are referred by their doctors, other health professionals, or enter on their own initiative. The program is delivered at diverse settings including hospitals, municipality clinics, general practices, pharmacies, and companies. It consists of five manual-based face-to-face sessions along with supportive medications over six weeks.

As a general principle, a patient is often considered as having completed a treatment program, if patient compliance/ adherence to the program is at least $75 \%$. This compliance level has been used for our smoking cessation program GSP, and for evaluating the program effectiveness at the national level in a previous study (7). However, the appropriateness of this compliance level has never been evaluat- 


\section{Research and Best Practice}

ed before. Therefore, the main aim of this study is to evaluate the evidence for this compliance level. Counselling compliance is one of the specified predictors for smoking cessation in the literature (8). In a meta-analysis of 45 studies, smoking cessation rates increased with the increase in the number of counselling sessions attended (8). The literature therefore indicates an established relationship between intensity in terms of program duration and/or number of sessions and effectiveness of the smoking cessation interventions (8-11). Nevertheless, there is little evidence on typical number and duration of smoking cessation interventions (10;12).

\section{Objectives}

- The primary objective was to investigate whether smokers completing at least $75 \%$ of the smoking cessation intervention had higher quit rates after 6 months than smokers participating in less than $75 \%$ of the program.

- The secondary objective was to investigate whether there might be a more appropriate compliance level than the $75 \%$ compliance level.

\section{Methods}

\section{The Gold Standard Program}

This is a standardised program in terms of setting a standard orientation and training program for all smoking cessation counsellors who are responsible for delivering the Standard Smoking Cessation Program, standardised delivery of the program aided with a manual and standardised data collection procedure (3).

\section{Patients}

In total, 299 smoking cessation units provided patient data to the Smoking Cessation Database (SCDB) in Denmark. While 23,775 daily smokers who had enrolled in the GSP from 2006-2009, 6,336 (26\%) were not included in this study, because some smoking cessation clinics had a priori decided not to follow-up on any of their patients. After 6 months, the included patients were contacted by phone and asked about their quitting status; at least four attempts including one in the evening were initiated to contact the patient. Only if all of the attempts failed was the patients' quitting outcome considered as missing (approximately $15 \%$ of patients) (Figure 1).

\section{Main independent variable}

The main exposure is the different compliance levels expressed as the number of sessions attended; data on attendance was entered into the SCDB for almost all patients since 2006.
Figure 1 Trial Profile

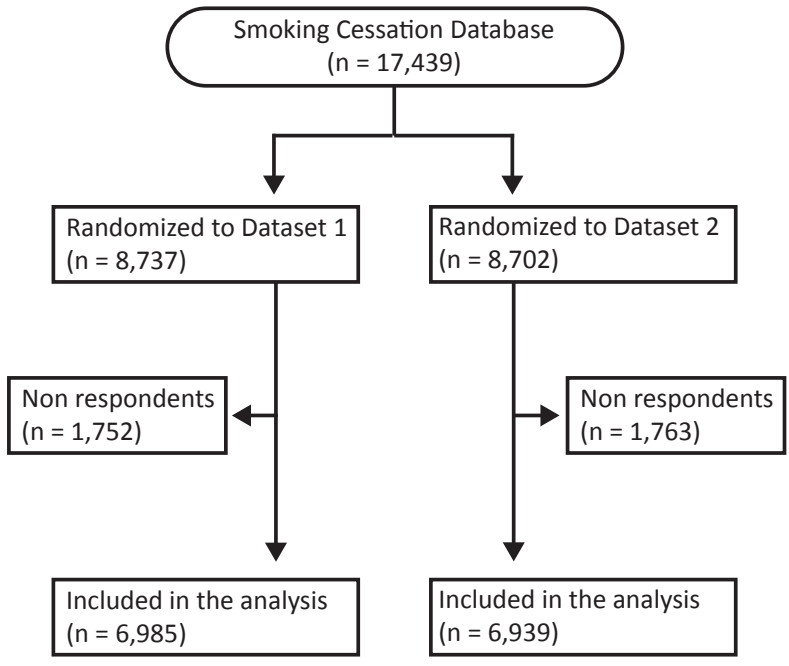

Quitting outcome measure

Patients were grouped according to the availability of 6-month follow up data on quitting outcomes into two "follow-up outcome" groups:

a) Patients with existing data on quitting outcomes at 6-months of follow up (base case scenario).

b) Patients with missing quitting outcome data due to failed follow-up attempts (non-responders). This group has been used in sensitivity analyses as worst and best case scenarios.

\section{Design}

We undertook a national population study using prospectively recorded data on patients and GSP characteristics. Patients' data was stratified by gender, age, and calendar year, and then randomly split into two datasets by a colleague not otherwise involved in the project. It is worth mentioning that population studies often generate many significant results, which requires further evaluation in new studies for confirmation. To overcome this methodological problem, we decided a priori to generate two datasets (dataset 1 and dataset 2) through random splitting of the original data in the SCDB; the second dataset was concealed from the researchers until the analysis of the first dataset had been finalised (Figure 1).

\section{Statistical methods}

The following analyses were performed and finalised for the first dataset "dataset 1", then repeated for the second dataset "dataset 2". Initially, logistic regression (LR) models were constructed, and two analyses compared the quit rates between different levels of compliance. The first analysis tested the primary objective and compared patients who completed less than $75 \%$ of the 


\section{Research and Best Practice}

program (i.e. one, or two, or three sessions) and who attended at least $75 \%$ of the program (four or five sessions); using patients who attended less than $75 \%$ of sessions as the reference group. The second analysis tested the secondary objective and compared the quit rates for patients who attended one, two, three, four, or five sessions; using the last group as the reference group. The set of predictors used in the LR models along with level of compliance were; smoking cessation unit setting, calendar year, intervention type, setting, if relapse prevention strategy offered for the patient, if nicotine replacement therapy offered to the patient, age, gender, overall Fagerström score, smoking years, living with smoker, living with adult, living with child, previous attempts to stop smoking, employment status, level of education, and housing type. It is worth mentioning that predictors have been chosen after screening of relevant literature (7;12-14).

Two sensitivity analyses (worst- and best-case scenarios) were performed on both datasets by including the data on non-respondents. The worst-case scenario considered non-responding patients as smokers, while the best-case scenario considered them as quitters. Statistical analysis was undertaken using SPSS 19.

\section{Ethical considerations}

Written informed consent in the national language was obtained from all patients who participated in the smoking cessation interventions. SCDB is registered at the Scientific Ethical Committee (Prot.-Nr. H-CFSP-2010-049). All data were analysed anonymously. The whole procedure on obtaining, storing, and utilising patients' information by the National Clinical Smoking Cessation Database Secretariat was approved by the Danish Data Protection Agency (J.-Nr. 2010-41-5463).

\section{Results}

\section{Statistics on comparability of groups}

Comparison of the different patient groups in terms of follow-up (base case and non-respondents) showed that the groups were similar for patient and program related characteristics, and for the two datasets (Table 1).

\section{Quitting outcomes data}

Table 2 shows quit rates at 6-months follow up in relation to different levels of compliance for the base case, and non-respondents (worst and best cases).

\section{Main Results}

Table 3 shows the main results along with results of the sensitivity analyses. Table 4 shows predictors of the relationship between compliance and quit rates on the two study objectives and for the two datasets.

\section{Primary objective}

Considering the base case scenario in both datasets 1 and 2, patients who completed at least $75 \%$ of the preplanned sessions (attended four or five sessions) had almost triple the quit rates in comparison to patients who attended less than $75 \%$ of pre-planned sessions (OR = 0.31 ; 95\% CI 0.27 - 0.35, and 0.27 ; 0.24 - 0.31, for the first and second datasets) (See Table 3).

\section{Secondary objective}

Considering the base case scenario in both datasets 1 and 2, patients who attended one, two, three, or four sessions had a lower probability of quitting compared to patients who completed the whole program. For instance, patients who completed only $75 \%$ of the program (four sessions) had a lower probability of quitting (almost half) compared to patients who completed 100\% of the program by attending all the five sessions ( 0.49 ; $0.43-0.56$, and $0.54 ; 0.47-0.62$, for the first and second datasets) (Table 3 ).

These results indicated an association between higher compliance levels and higher quit rates (Figure 2).

Figure 2 Adjusted ORs estimates on the secondary objective for both datasets*

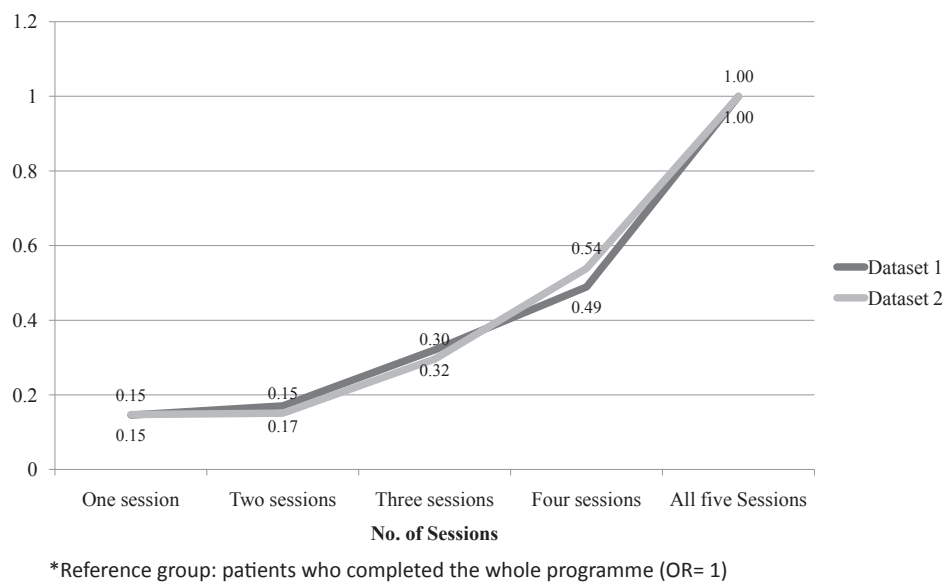

\section{Sensitivity analyses}

Primary objective: In both datasets 1 and 2, the best and worst-case scenarios showed similar results to the base case scenario. Results showed that attending less than $75 \%$ of the pre-planned sessions was associated with a lower probability of quitting compared with attending at least $75 \%$ (at least four) sessions (Table 3). 


\section{Research and Best Practice}

Table 1 Population cohort main characteristics in the two datasets, given in numbers (\%) or median (range)

\begin{tabular}{|c|c|c|c|c|}
\hline \multirow{2}{*}{$\begin{array}{l}\text { Dataset } \\
\text { Patient group }\end{array}$} & \multicolumn{2}{|c|}{ Dataset $1(\mathrm{~N}=8,737)$} & \multicolumn{2}{|c|}{ Dataset $2(\mathrm{~N}=8,702)$} \\
\hline & Base Case & Non-respondents & Base Case & Non-respondents \\
\hline Count & 6985 & 1752 & 6939 & 1763 \\
\hline Percent of the total count $\%$ & 58.6 & 14.7 & 58.5 & 14.8 \\
\hline \multicolumn{5}{|l|}{ Characteristics } \\
\hline \multicolumn{5}{|l|}{ Unit Type \% } \\
\hline Pharmacy & 24.9 & 23.2 & 24.7 & 25.4 \\
\hline Hospital Clinic incl. Midwives & 10.8 & 10.4 & 10.9 & 9.8 \\
\hline Municipality and other practices & 59.3 & 63.7 & 59.0 & 61.5 \\
\hline County coordinator & 5.0 & 2.7 & 5.4 & 3.3 \\
\hline \multicolumn{5}{|l|}{ Year \% } \\
\hline 2006 & 23.9 & 20.0 & 23.7 & 21.2 \\
\hline 2007 & 28.1 & 28.5 & 27.8 & 27.0 \\
\hline 2008 & 24.1 & 26.7 & 24.6 & 26.3 \\
\hline 2009 & 24.0 & 24.8 & 23.9 & 25.6 \\
\hline \multicolumn{5}{|l|}{ Intervention type \% } \\
\hline Individual & 8.0 & 8.2 & 8.1 & 9.9 \\
\hline Group and other interventions & 92.0 & 91.8 & 91.9 & 90.1 \\
\hline \multicolumn{5}{|l|}{ Relapse Prevention \% } \\
\hline No & 51.1 & 57.7 & 51.3 & 60.1 \\
\hline Yes & 48.9 & 42.3 & 48.7 & 39.9 \\
\hline \multicolumn{5}{|l|}{ Nicotine Replacement \% } \\
\hline No & 51.3 & 46.5 & 51.8 & 49.1 \\
\hline Yes & 48.7 & 53.5 & 48.2 & 50.9 \\
\hline \multicolumn{5}{|l|}{ Age \% } \\
\hline Less than 35 & 14.2 & 21.4 & 13.6 & 22.1 \\
\hline From 35 to 54 & 43.7 & 44.2 & 45.1 & 44.8 \\
\hline More than 55 & 37.8 & 29.9 & 36.6 & 29.8 \\
\hline Missing Data & 4.3 & 4.6 & 4.6 & 3.3 \\
\hline \multicolumn{5}{|l|}{ Gender \% } \\
\hline Women & 61.7 & 60.9 & 62.3 & 61.7 \\
\hline Men & 38.3 & 39.1 & 37.7 & 38.3 \\
\hline \multicolumn{5}{|l|}{ Fagerström Score \% } \\
\hline From 0 to 4 & 38.4 & 38.0 & 37.6 & 35.0 \\
\hline From 5 to 10 & 61.6 & 62.0 & 62.4 & 65.0 \\
\hline \multicolumn{5}{|l|}{ Living with smoker \% } \\
\hline No & 64.8 & 67.6 & 64.7 & 64.8 \\
\hline Yes & 34.5 & 31.5 & 34.6 & 34.7 \\
\hline Missing & .7 & .9 & .7 & .5 \\
\hline \multicolumn{5}{|l|}{ Living with adult \% } \\
\hline No & 43.2 & 48.0 & 44.4 & 47.2 \\
\hline Yes & 55.7 & 50.8 & 54.6 & 51.8 \\
\hline Missing Data & 1.1 & 1.2 & 1.0 & 1.0 \\
\hline
\end{tabular}


Research and Best Practice

\begin{tabular}{|c|c|c|c|c|}
\hline \multicolumn{5}{|l|}{ Living with child \% } \\
\hline No & 66.5 & 69.1 & 66.9 & 66.8 \\
\hline Yes & 32.3 & 29.6 & 32.1 & 32.3 \\
\hline Missing Data & 1.2 & 1.4 & & 1.0 \\
\hline \multicolumn{5}{|l|}{ Previous quitting attempts \% } \\
\hline Non & 38.9 & 40.5 & 39.2 & 39.1 \\
\hline 1-3 times & 49.4 & 48.1 & 49.9 & 49.1 \\
\hline more than 3 times & 9.9 & 9.0 & 9.2 & 9.0 \\
\hline Missing Data & 1.8 & 2.3 & 1.6 & 2.8 \\
\hline \multicolumn{5}{|l|}{ Employment status \% } \\
\hline with job & 63.2 & 63.0 & 63.1 & 60.6 \\
\hline without job & 34.6 & 34.0 & 34.4 & 36.6 \\
\hline Missing Data & 2.2 & 3.1 & 2.5 & 2.8 \\
\hline \multicolumn{5}{|l|}{ Education \% } \\
\hline lower education = less than 11 years & 59.8 & 58.4 & 60.2 & 63.0 \\
\hline higher and other education & 37.2 & 38.0 & 36.7 & 33.5 \\
\hline Missing Data & 3.0 & 3.6 & 3.1 & 3.6 \\
\hline \multicolumn{5}{|l|}{ Housing Type \% } \\
\hline Residential property+ other housing & 51.9 & 42.5 & 52.2 & 39.0 \\
\hline Co-operative dwelling & 9.0 & 11.4 & 8.9 & 10.4 \\
\hline Rented accommodation & 37.3 & 44.5 & 37.3 & 48.4 \\
\hline Missing Data & 1.7 & 1.6 & 1.6 & 2.2 \\
\hline Smoking (years) & $32(0-74)$ & $29(0-66)$ & $32(0-99)$ & $30(0-67)$ \\
\hline Compliance/attendance (meetings) & $4(1-5)$ & $3(1-5)$ & $4(1-5)$ & $3(1-5)$ \\
\hline
\end{tabular}

Table 2 Quit rates in the two datasets

\begin{tabular}{|c|c|c|c|c|c|c|}
\hline \multirow[b]{2}{*}{ Total count } & \multicolumn{3}{|c|}{ Dataset 1} & \multicolumn{3}{|c|}{ Dataset 2} \\
\hline & Base Case & Worst Case & Best Case & Base Case & Worst Case & Best Case \\
\hline & $n=6,985$ & $n=8,737$ & $n=8,737$ & $n=6,939$ & $n=8,702$ & $\mathrm{n}=8,702$ \\
\hline Quitters & 2266 & 2266 & 4018 & 2218 & 2218 & 3981 \\
\hline Percentage \% & 32.4 & 25.9 & 46.0 & 32.0 & 25.5 & 45.7 \\
\hline \multicolumn{7}{|l|}{$\begin{array}{l}\text { Compliance } \\
\text { /Attendance }\end{array}$} \\
\hline 1 Session & 0.8 & 0.6 & 4.1 & 0.8 & 0.6 & 4.1 \\
\hline 2 sessions & 1.5 & 1.2 & 4.3 & 1.4 & 1.1 & 4.4 \\
\hline 3 sessions & 3.7 & 2.9 & 6.7 & 3.4 & 2.7 & 6.4 \\
\hline 4 sessions & 7.9 & 6.3 & 10.8 & 8.2 & 6.5 & 10.9 \\
\hline 5 sessions & 18.5 & 14.8 & 20.1 & 18.2 & 14.5 & 19.9 \\
\hline Less than $75 \%$ & 6.0 & 4.8 & 15.1 & 5.6 & 4.5 & 14.9 \\
\hline At least $75 \%$ & 26.5 & 21.2 & 30.9 & 26.3 & 21.0 & 30.9 \\
\hline
\end{tabular}




\section{Research and Best Practice}

Table 3 Main results along with the two sensitivity analyses; evaluating whether smokers completing at least $75 \%$ of the smoking cessation intervention had higher quit rates after 6 months than smokers participating in less than $75 \%$ of the program; and investigating whether there might be a more appropriate compliance level than the $75 \%$ compliance level (Please, observe that all results were significant). The value 1 was the reference.

\begin{tabular}{|c|c|c|c|c|c|c|}
\hline \multirow{2}{*}{ Scenario } & \multicolumn{3}{|c|}{ Dataset 1} & \multicolumn{3}{|c|}{ Dataset 2} \\
\hline & $\begin{array}{c}\text { OR } \\
(95 \% \mathrm{Cl})\end{array}$ & $\begin{array}{c}\text { OR } \\
(95 \% \mathrm{Cl})\end{array}$ & $\begin{array}{c}\text { OR } \\
(95 \% \mathrm{Cl})\end{array}$ & $\begin{array}{c}\text { OR } \\
(95 \% \mathrm{Cl})\end{array}$ & $\begin{array}{c}\text { OR } \\
(95 \% \mathrm{Cl})\end{array}$ & $\begin{array}{c}\text { OR } \\
(95 \% \mathrm{Cl})\end{array}$ \\
\hline$>75 \%$ Attendance & 1 & 1 & 1 & 1 & 1 & 1 \\
\hline$<75 \%$ Attendance & $0.31(0.27-0.35)$ & $0.29(0.25-0.33)$ & $0.64(0.58-0.71)$ & $0.27(0.24-0.31)$ & $0.27(0.24-0.31)$ & $0.57(0.52-0.63)$ \\
\hline 4 sessions & $0.49(0.43-0.56)$ & $0.49(0.43-0.56)$ & $0.61(0.54-0.69)$ & $0.54(0.47-0.62)$ & $0.54(0.48-0.62)$ & $0.66(0.58-0.74)$ \\
\hline 3 sessions & $0.32(0.27-0.38)$ & $0.32(0.27-0.37)$ & $0.52(0.45-0.59)$ & $0.30(0.25-0.35)$ & $0.31(0.26-0.37)$ & $0.46(0.40-0.53)$ \\
\hline 2 sessions & $0.17(0.14-0.22)$ & $0.17(0.13-0.21)$ & $0.43(0.37-0.50)$ & $0.15(0.12-0.19)$ & $0.15(0.12-0.19)$ & $0.42(0.36-0.49)$ \\
\hline 1 session & $0.15(0.11-0.20)$ & $0.11(0.08-0.16)$ & $0.69(0.58-0.83)$ & $0.15(0.11-0.20)$ & $0.12(0.09-0.17)$ & $0.64(0.54-0.76)$ \\
\hline
\end{tabular}

Table 4 Predictors on the association between attendance and quitting rates for smokers completing at least $75 \%$ of the smoking cessation intervention and for smokers attending all sessions. The value 1 was the reference.

\begin{tabular}{|c|c|c|c|c|c|c|c|c|}
\hline & \multicolumn{4}{|c|}{$\begin{array}{l}\text { Attendance and quitting rates for smokers completing at } \\
\text { least } 75 \% \text { of the smoking cessation intervention }\end{array}$} & \multicolumn{4}{|c|}{ Smokers attending all sessions } \\
\hline & \multicolumn{2}{|c|}{ Dataset 1} & \multicolumn{2}{|c|}{ Dataset 2} & \multicolumn{2}{|c|}{ Dataset 1} & \multicolumn{2}{|c|}{ Dataset 2} \\
\hline & & $95 \% \mathrm{Cl}$ & & $95 \% \mathrm{Cl}$ & $95 \% \mathrm{Cl}$ & & $95 \% \mathrm{Cl}$ & \\
\hline \multicolumn{9}{|l|}{ Unit Type } \\
\hline Pharmacy & 0.090 & $1.27(0.93-1.73)$ & 0.034 & 1.39 (1.03-1.89) & 0.104 & $1.26(0.92-1.72)$ & 0.049 & $1.36(1.00-1.85)$ \\
\hline Hospital Clinic incl. Midwives & 0.079 & $1.31(0.94-1.84)$ & 0.009 & $1.57(1.12-2.20)$ & 0.087 & $1.35(0.96-1.90)$ & 0.006 & $1.61(1.14-2.26)$ \\
\hline Municipality and other practices & 0.120 & $1.23(0.91-1.67)$ & 0.006 & $1.52(1.13-2.05)$ & 0.110 & $1.25(0.92-1.69)$ & 0.012 & $1.47(1.09-1.99)$ \\
\hline \multicolumn{9}{|l|}{ Year } \\
\hline 2009 & - & 1 & - & 1 & - & 1 & - & 1 \\
\hline 2006 & 0.016 & $0.80(0.67-0.96)$ & 0.635 & $1.01(0.84-1.22)$ & 0.017 & $0.80(0.66-0.96)$ & 0.685 & $1.00(0.83-1.20)$ \\
\hline 2007 & 0.070 & $0.87(0.74-1.01)$ & 0.097 & $0.89(0.76-1.04)$ & 0.085 & $0.87(0.74-1.02)$ & 0.092 & $0.87(0.74-1.02)$ \\
\hline 2008 & 0.000 & $0.71(0.61-0.84)$ & 0.063 & $0.86(0.73-) 1.01$ & 0.000 & $0.72(0.61-0.85)$ & 0.059 & $0.85(0.72-1.01)$ \\
\hline \multicolumn{9}{|l|}{ Intervention type } \\
\hline Group and others & - & 1 & - & 1 & - & 1 & - & 1 \\
\hline Individual & 0.017 & $1.29(1.05-1.60)$ & 0.094 & $1.18(0.95-1.46)$ & 0.0875 & $1.18(0.95-1.47)$ & 0.285 & $1.10(0.88-1.36)$ \\
\hline \multicolumn{9}{|l|}{ Relapse Prevention } \\
\hline Yes & & 1 & & 1 & - & 1 & - & 1 \\
\hline No & 0.070 & $0.90(0.79-1.01)$ & 0.072 & $0.89(0.79-1.01)$ & 0.089 & $0.91(0.81-1.03)$ & 0.0909 & $0.91(0.81-1.03)$ \\
\hline \multicolumn{9}{|l|}{ Nicotine Replacement } \\
\hline Yes & - & 1 & - & 1 & - & 1 & - & 1 \\
\hline No & 0.321 & 0.95 (0.84-1.09) & 0.658 & $1.00(0.88-1.15)$ & 0.282 & $0.95(0.83-1.08)$ & 0.6139 & $1.01(0.88-1.15)$ \\
\hline \multicolumn{9}{|l|}{ Age } \\
\hline $35-54$ & 0.025 & $0.82(0.69-0.98)$ & 0.069 & $0.86(0.72-1.03)$ & 0.011 & $0.71(0.55-0.92)$ & 0.064 & $0.77(0.59-1.02)$ \\
\hline$<35$ & 0.004 & $0.68(0.53-0.88)$ & 0.036 & $0.75(0.57-0.98)$ & 0.045 & $0.84(0.70-1.00)$ & 0.143 & $0.89(0.75-1.06)$ \\
\hline
\end{tabular}




\section{Research and Best Practice}

\begin{tabular}{|c|c|c|c|c|c|c|c|c|}
\hline Gender & & & & & & & & \\
\hline Men & - & 1 & - & 1 & - & 1 & - & 1 \\
\hline Women & 0.000 & $0.76(0.68-0.86)$ & 0.000 & $0.81(0.72-0.91)$ & 0.000 & $0.78(0.69-0.88)$ & 0.000 & $0.81(0.71-0.91)$ \\
\hline \multicolumn{9}{|l|}{ Fagerström Score } \\
\hline High ( 5-10 points) & - & 1 & - & 1 & - & 1 & - & 1 \\
\hline Low (0-4 points) & 0.000 & $1.38(1.23-1.55)$ & 0.000 & 1.49 (1.32-1.67) & 0.000 & $1.38(1.23-1.55)$ & 0.000 & $1.49(1.32-1.68)$ \\
\hline Smoking Years & 0.000 & $0.99(0.98-0.99)$ & 0.003 & $0.99(0.98-1.00)$ & 0.000 & 0.99 (0.98-0.99) & 0.002 & $0.99(0.98-1.00)$ \\
\hline \multicolumn{9}{|l|}{ Living with smoker } \\
\hline Yes & - & 1 & - & 1 & - & 1 & - & 1 \\
\hline No & 0.006 & $1.19(1.05-1.36)$ & 0.123 & $1.09(0.96-1.24)$ & 0.010 & $1.18(1.04-1.35)$ & 0.101 & $1.10(0.97-1.25)$ \\
\hline \multicolumn{9}{|l|}{ Living with adult } \\
\hline Yes & - & 1 & - & 1 & - & 1 & - & 1 \\
\hline No & 0.052 & $0.88(0.78-1.00)$ & 0.043 & $0.88(0.77-1.00)$ & 0.094 & $0.90(0.79-1.02)$ & 0.041 & $0.87(0.77-0.99)$ \\
\hline \multicolumn{9}{|l|}{ Living with child } \\
\hline Yes & & 1 & & 1 & - & 1 & - & 1 \\
\hline No & 0.430 & $1.04(0.90-1.19)$ & 0.312 & $0.95(0.82-1.09)$ & 0.547 & $1.02(0.88-1.18)$ & 0.272 & $0.94(0.81-1.08)$ \\
\hline \multicolumn{9}{|l|}{ Previous attempts to stop smoking } \\
\hline More than 3 times & - & 1 & - & 1 & - & 1 & - & 1 \\
\hline Non & 0,140 & $0.88(0.72-1.07)$ & 0.693 & $1.00(0.82-1.23)$ & 0.138 & $0.88(0.72-1.07)$ & 0.659 & $0.99(0.81-1.22)$ \\
\hline 1-3 times & 0.031 & $0.81(0.67-0.98)$ & 0.383 & $0.94(0.77-1.15)$ & 0.029 & $0.81(0.67-0.98)$ & 0.351 & $0.93(0.77-1.14)$ \\
\hline \multicolumn{9}{|l|}{ Employment status } \\
\hline Non-Employed & - & 1 & - & 1 & - & 1 & - & 1 \\
\hline Employed & 0.039 & $1.16(1.01-1.34)$ & 0.331 & $1.05(0.91-1.22)$ & 0.050 & $1.15(1.00-1.33)$ & 0.264 & $1.07(0.92-1.24)$ \\
\hline \multicolumn{9}{|l|}{ Education } \\
\hline Higher & - & 1 & - & 1 & - & 1 & - & 1 \\
\hline Lower (<11 years) & 0.059 & $0.89(0.79-1.00)$ & 0.000 & $0.81(0.72-0.91)$ & 0.047 & $0.89(0.79-1.00)$ & 0.000 & $0.80(0.71-0.90)$ \\
\hline \multicolumn{9}{|l|}{ Housing Type } \\
\hline Rented accommodation & - & 1 & - & 1 & - & 1 & - & 1 \\
\hline Residential property and others & 0.000 & $1.28(1.12-1.45)$ & 0.000 & $1.36(1.19-1.55)$ & 0.000 & $1.28(1.13-1.46)$ & 0.000 & $1.34(1.18-1.53)$ \\
\hline Co-operative dwelling & 0.249 & $1.10(0.89-1.36)$ & 0.584 & $1.02(0.82-1.28)$ & 0.268 & $1.10(0.89-1.36)$ & 0.511 & $1.04(0.83-1.30)$ \\
\hline
\end{tabular}

Secondary objective: In both datasets 1 and 2, the worstcase scenario had similar results to the base-case scenario results. The best-case was quite different on the first session. Nevertheless, the results from the best-case scenario were reflecting the same findings as the basecase and worst-case scenarios; attending less than five sessions (from one to four sessions) was associated with a lower probability of quitting compared with attending all the pre-planned five sessions (Table 3).

\section{Discussion}

We found that the results supported the principle of defining completion of the smoking cessation intervention as completion of at least $75 \%$ of sessions, while completing the whole intervention (all sessions) was associated with even better outcomes. The obtained results were robust to sensitivity analyses. The total quit rate was $32 \%$ (base-case scenario), originating from $26 \%$ of those with at least $75 \%$ compliance and $6 \%$ from those attending less than $75 \%$ of the meetings.

Considering our base-case scenario for both datasets, the observed quit rates were relatively comparable to results reported in similar studies conducted in Canada and the USA (32\% quit rate for 8 sessions program, and $21 \%$ for 4-8 sessions' programs, respectively) (1517). The 'dose-response relation' shown in figure 2 between higher completion of the programme and better quit-rate could be a direct consequence of that those, who spent more time on smoking cessation intervention received a higher dosage of effective intervention and thereby got a better outcome. Another part of the explanation on the 'dose-response relation' could be that 
participants, who continued to smoke or relapsed after a short quitting would to a higher degree stay away from the following sessions, while only the quitters would take part of the programme. This study can not give the answer, and further studies on attitudes and experiences would be required.

We did not validate quit rates using the carbon monoxide "CO" test. However, in two studies from the UK and USA, the difference between self-reported and "CO" validated quit rates were minor (16;18-19). Moreover, evaluating UK NHS short and long term smoking quit rates showed that there was only a very minor increase in non-quit rates when including participants whose selfreported quitting was disproved by $\mathrm{CO}$ test ( $0.5 \%$ and $0.2 \%$ for short and long term quit rates, consecutively). $(16 ; 19)$ In a systematic review on the effectiveness of the UK NHS smoking cessation services reported cessation rates of around 60\% for self-reporters and 53\% for "CO" validated rates over four weeks (short term outcome), and around $17 \%$ for self-reporters and $15 \%$ for "CO" validated rates over one year (long term outcome)(20). It is worth noting that the study on long term (one year outcome) effectiveness of NHS smoking services included only self-reported quitters who quit in the short term (four weeks) (20), while our study included all patients' outcomes at six months, irrespective of short term outcomes. Indeed, the total quit rate (32\%) in our study was high compared to previous literature (10), even when compared with the above studies from the UK where the long term follow up only included short term quitters (20).

In a US study on short-and long-term smoking cessation for different levels of intensity of behavioural treatment, biochemically confirmed quit rates at 26 weeks followup were higher for the high intensity program compared with less intense interventions (21). In a large systematic review concerning setting guidelines on "Treating Tobacco Use and Dependence in the USA", it was concluded from included meta-analyses that provision of at least four sessions enhances quit rates compared with provision of fewer sessions (10). Another study from the USA found that comprehensive prolonged smoking treatment programs that combine medications and psychological approaches are able to produce higher quit rates than those reported in the literature (4). Indeed, the significant increase in quit rates associated with different degrees of program completeness in our study could partly be explained by the structure of the GSP itself. It is manual-based and includes most of the prognostic factors that influence the success of quitting attempts, such as qualified counselling, nicotine replacement ther- apy, and relaps prevention strategies. Hence, the longer a participant remains in the GSP, the more prognostic factors are addressed. Another possible explanation for the association is that some of the patients who did not quit may have stopped participating in the GSP before those who managed to quit. On the other hand, some of the early quitters may not feel they need to complete the treatment program. A further strength of the study is that all relevant aspects of the GSP were standardised across all smoking cessation treatment centres.

It is worth considering that this study is a large nationwide population study and thereby results can be generalised to the country as a whole. However, our results should be interpreted with caution when generalising the results to other countries with different smokers, settings, and intervention programs. It is also worth noting that this is not a randomised controlled trial. Other strengths are that the study includes both genders, all age groups, wide geographic coverage, smokers from different socio-economic groups, cover long-term follow-up period (6 months), and data was prospectively collected.

Regarding the study design, predictive models were developed on data simulated from the population included in the database. The utilisation of a validation cohort "dataset 2" was helpful to avoid relying on what could be optimistic or underestimated OR estimates from "dataset 1 " on the association between compliance levels and quit rates. Yet, statistical modelling used for data analysis represents a simplified illustration of reality; consequently, many unforeseen variables that represent predictors and confounders related to the quit rates, could exist and not be included in the model (22). Thus, there is still a possibility that this study finding could be either overestimating or underestimating the real results. Nevertheless, the LR models have been validated (goodness of fit) by using the second dataset "dataset 2 " which showed similar results to the first dataset "dataset 1 "(22).

Concerning the clinical population cohort, this study used only data from a four-year period, as data on compliance/attendance was not routinely collected prior to this. Missing data on quitting outcomes was considered in the data analysis strategy according to the reason for the missing data. Another group of patients without planned follow-up due to lack of resources by the smoking cessation unit was not evaluated. The fact that some patients were not routinely followed up represents a potential weakness in the study. However, the results on the two tested objectives from the two sensitivity analyses showed similar findings to the base case sce- 
nario. Moreover, patient data on different predictors for quitting has been collected and recorded for almost all included patients, which represents strength. In future studies, the generalisability of study findings may be enhanced by research cooperation with similar programs that have similar interventions and databases in other countries.

\section{Implications}

From a clinical perspective, it is important to reinforce the advice to adhere to at least $75 \%$ of the pre-planned sessions. However, to maximize the benefit from attending this program, patients should be encouraged to attend the whole program. Crucially, in terms of achieving the highest quit rates, there is a need for changes in tobacco control strategies implied by healthcare personnel and policy makers, where more attention should be given to maintain patients in smoking treatment programs instead of only recruiting them into such programs. Smoking cessation units that have chosen not to follow up on their patients should be supported in increasing their follow-up to improve the quality of further studies. The high participation rate in data collection by smoking cessation counsellors from a wide range of diverse units in Denmark enhances the generalisability of the results, and the ownership of this research study, which may encourage uptake of the results into practice.

From a research point of view further qualitative and quantitative research is needed to investigate predictors on different compliance levels and what triggers higher and lower compliance by patients who are participating in the GSP. Additionally, missing data on quit rates could be addressed through a separate study, specifically analysing missing quitting outcomes (23). It is also important to evaluate different contextual factors and social phenomena involved with the GSP. Integrating such quantitative and qualitative research findings could contribute to the amount of available evidence on compliance as a key predictor of smoking cessation. In addition, such research may be used to identify possible mechanisms to establish a long-term relationship with patients to reinforce important messages concerning smoking cessation and sustained quitting (24).

\section{Acknowledgements}

This study received a valuable input from Dr. Patrick Fitzgerald from the Section of Health Economics and Decision Science Section, School of Health and Related Research at the University of Sheffield, UK.

\section{References}

(1) Adults' smoking habits. Danish Cancer Society [ 2011 [cited 2011 Apr. 8]; Available from: www.cancer.dk

(2) Danish Smoking Cessation Database. Rygestopbasen 2011 [cited 2012 Dec. 8]; Available from: www.rygestopbasen.dk

(3) Neumann T, Rasmussen M, Ghith N, Heitmann BL, Tønnesen H. The Gold Standard Programme: smoking cessation interventions for disadvantaged smokers are effective in a real-life setting. Tobacco Control 2011:050194 (open access) (4) Hall SM, Humfleet GL, Reus VI, Munoz RF, Cullen J. Extended nortriptyline and psychological treatment for cigarette smoking. American Journal of Psychiatry 2004; $161: 2100$

(5) Steinberg MB, Foulds J, Richardson DL, Burke MV, Shah P. Pharmacotherapy and smoking cessation at a tobacco dependence clinic. Preventive medicine 2006 42:114-119.

(6) Rigotti NA, Munafo MR, Stead LF. Smoking Cessation Interventions for Hospitalized Smokers: A Systematic Review. Arch Intern Med 2008; 168:1950-1960. (7) Kjaer NT, Evald T, Rasmussen M, Juhl HH, Mosbech H, Olsen KR. The effectiveness of nationally implemented smoking interventions in Denmark. Preventive medicine 2007; 45:12-4.

(8) Fiore MC, Bailey WC, Cohen SJ, Dorfman SF, Goldstein MG, Gritz ER. Treating Tobacco Use and Dependence: A Clinical Practice Guideline. Rockville, MD: US Department of Health and Human Services; 2000. Public Health Service June 2000. (9) Fiore MC, McCarthy DE, Jackson TC, Zehner ME, Jorenby DE, Mielke M, et al. Integrating smoking cessation treatment into primary care: an effectiveness study. Preventive medicine 2004; 38:412-20.

(10) Fiore MC, Jaen CR, Baker TB, Bailey WC, Curry SJ. Treating Tobacco Use and Dependence: 2008 Update Rockville. MD: US Dept of Health and Human Services 2008.

(11) Barth J, Bengel J, Critchley J. Efficacy of psychosocial interventions for smoking cessation in patients with coronary heart disease: a systematic review and meta-analysis. Annals of Behavioral Medicine 2006; 32:10-20.

(12) Miller M, Wood L. Effectiveness of smoking cessation interventions: review of evidence and implications for best practice in Australian health care settings. Australian and New Zealand journal of public health 2003; 27:300-309.

(13) Pisinger C, Vestbo J, Borch-Johnsen K, Jorgensen T. Smoking cessation intervention in a large randomised population-based study. The Inter99 study. Preventive medicine 2005; 40:285-92.

(14) Zimmermann E, Ekholm O, Juel K, Curtis T. Predictors of smoking cessation in a national representative random sample of Danish adults]. Ugeskrift for laeger 2006; 168:3615.

(15) Fiore MC, Jaen CR, Baker TB, Bailey WC, Benowitz NL, Curry SJ, et al. Treating tobacco use and dependence: 2008 update US Public Health Service Clinical Practice Guideline executive summary. Respir Care 2008; 53:1217-22.

(16) Ferguson J, Bauld L, Chesterman J, Judge K. The English smoking treatment services: one-year outcomes. Addiction 2005; 100:59-69.

(17) Carlson LE, Taenzer P, Koopmans J, Bultz BD. Eight-year follow-up of a community-based large group behavioral smoking cessation intervention. Addictive behaviors 2000; 25:725-41.

(18) Simon JA, Carmody TP, Hudes ES, Snyder E, Murray J. Intensive smoking cessation counseling versus minimal counseling among hospitalized smokers treated with transdermal nicotine replacement: a randomized trial* 1 . The American journal of medicine 2003; 114:555-62.

(19) Judge K, Bauld L, Chesterman J, Ferguson J. The English smoking treatment services: short-term outcomes. Addiction 2005; 100:46-58.

(20) Bauld L, Bell K, McCullough L, Richardson L, Greaves L. The effectiveness of NHS smoking cessation services: a systematic review. Journal of Public Health 2010; 32:71.

(21) Alterman Al, Gariti P, Mulvaney F. Short-and Long-Term Smoking Cessation for Three Levels of Intensity of Behavioral Treatment* 1. Psychology of Addictive Behaviors 2001; 15:261-4.

(22) Hosmer DWJ, Lemeshow S. Applied Logistic Regression. 2004.

(23) Faris PD, Ghali WA, Brant R, Norris CM, Galbraith PD, Knudtson ML. Multiple imputation versus data enhancement for dealing with missing data in observational health care outcome analyses. Journal of clinical epidemiology 2002; 55:184-91.

(24) Worcester MUC, Stojcevski Z, Murphy B, Goble AJ. Long-term behavioral outcomes after attendance at a secondary prevention clinic for cardiac patients. Journal of Cardiopulmonary Rehabilitation and Prevention 2003; 23:415.

\section{Competing Interests}

None declared. 